\title{
دور تصميم مادة الإملاء \\ لطلاب السنة الأولى بكلية المعلمين الإسلامية لترقية مهارة الكتابة
}

Asrofik

asyrof.biek@yahoo.com

جامعة مولانا مالك إبراهيم الإسلامية الحكومية مالانج

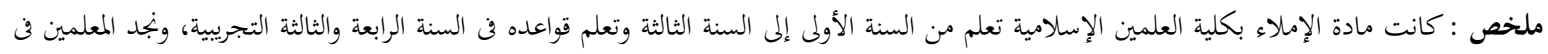

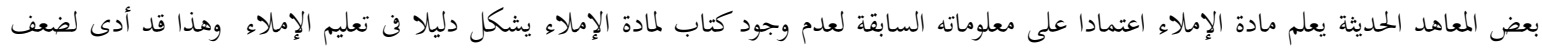

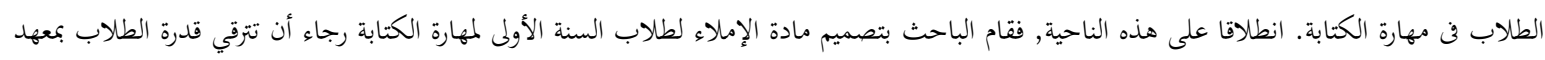

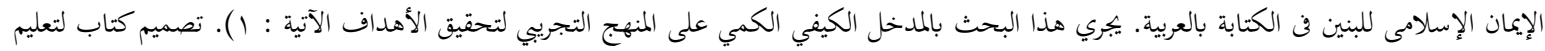

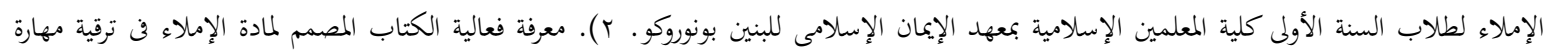

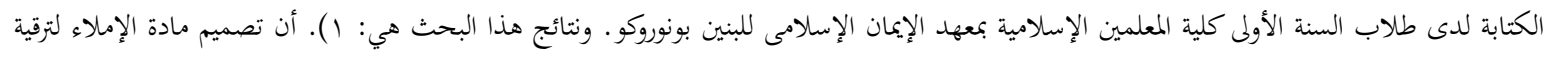

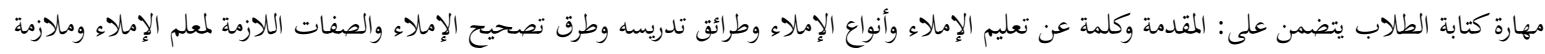

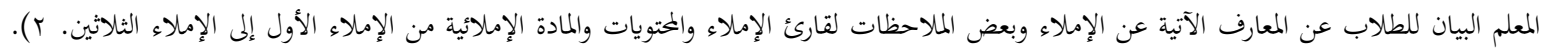

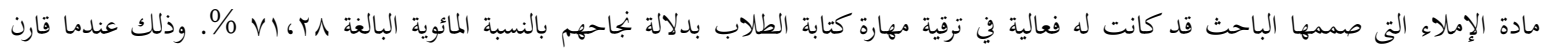

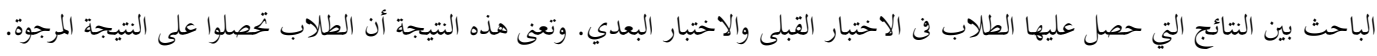

الكلمات المفتاح: الإملاء, مهارة الكتابة, التصميم.

خريجوا معهد الإيمان الإسلامى كل عام

\section{مقدّمة}

دراسي خدمته سنة أو أكثر في نفس المعهد

المدرس يقوْم بعملٍ جليْلٍ هو خِذْمةُ

أو فن المعاهد الأخرى بسائر أنحاء جزر

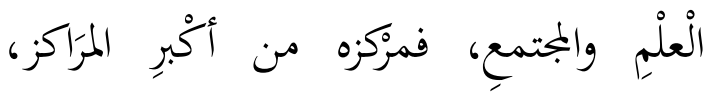

إندونيسيا. ويتوفر النفع لكتاب دروس اللغة

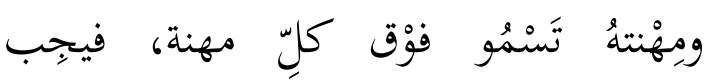

العربية على الطريقة الحديثة الجزء الأول وغيره

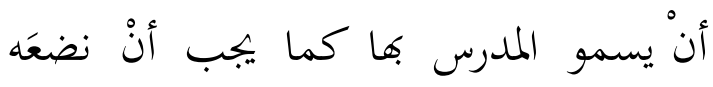

من المواد الدراسية في هذا المعهد وفى جميع

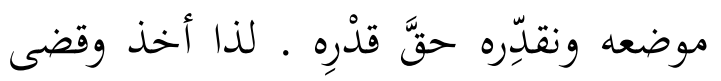

المعاهد الإسلامية التى أُسِسـست بخريجي المعهد

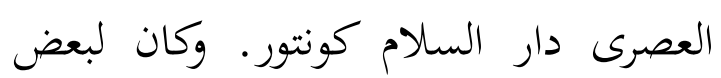

' ' محمود عطية الإبراشي. روح التربية والتعليم. (القاهرة. دار الفكر العربي. . $) \leqslant 9:$ : (1994 
الابتدائى، فييختلف ما بحثه أشرف بيك عنهم الذى قام ببحثه في كلية المعلمين الإسلامية أي المستبوى المتوسطى.

الإطار النظري مفهوم مهارة الكتابة. مهارة الكتابة هى احدى المهارات الايجابية والابداعية. تبدأ مراحلها برسم الحروف والكلمات والجمل وتنتهى بالتعبير الحر. وهذه المهارة تحتاج إلى عمليات ذهنية وتناسق حسي حركي يشابهان إلى حد بعيد

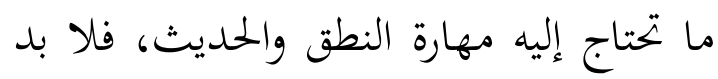
للكاتب والمتحدث من ترجمة أفكاره إلى رموز منطوقة في حالة الحديث ومدونة في حالة الكتابة حتى يوفر للسامع أو القارئ وسيلة اتصال تعينه على فهم ما يعنيه. ولذا تعتبر الكتابة مهارة ايجابية انتاجية تتطلب في من يزاولها معرفة بعناصر اللغة من قواعد ومفردات وسيطرة تامة على حسن اختبار ما

Yمادة إبراهيم. الاتجاهات المعاصرة في دروس اللغة اللعربية واللغات الحية

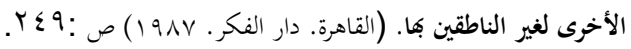

المادة كتابا أو دليلا للمعلم ولم يكن للبعض كما لم يكن الكتاب المعين لمادة الإملاء خاصة للفصل الأول، إلى أن يجعل هذا

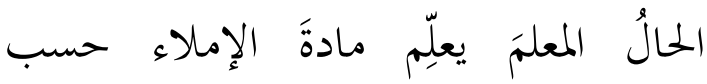

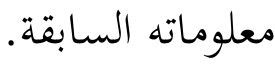

وسبق أن قام باحثون آخرون بالبحث في موضوع تصميم المادة التعليمية وتطويرها لمهارة الكتابة العربية، فمنهم مثلا؛

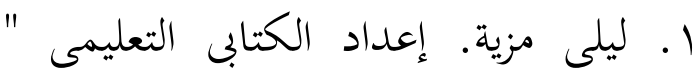
قواعد الخط العربي و الإملاء لتنمية مهارة

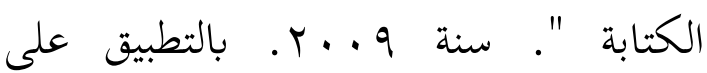
جامعة مالانق الحكومية. ب. تعمير المساجد. تصميم مادة التعليمية لمهارة الكتابة العربية لتلاميذ المرحلة الإبتدائية في ضوء المنهج على مستوى الوحدة الدراسية. سنة م ... والمادة التعليمية التى طورها هى مادة الإملاء للمستوى الإبتدائي.

تبين الدراسات السابقات بأها نوع من البحث والتنمية والبطويرية فن إعداد وتصميم المادة التعليمية لترقية مهارة الكتابة. كما قامت ليلى مزية ببحثها في المستوى الجامعى، وقام تعمير المساجد ببحثه فن المستوى 
أولا. التدرج: قالت راضية زين الدين

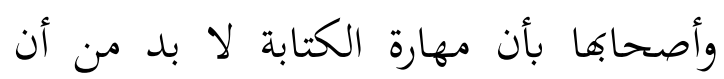

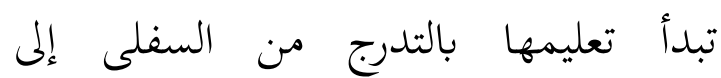

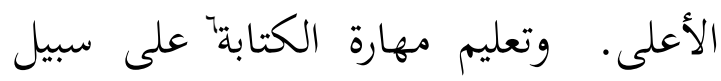

التدرج يبدأ ب: نقل الحرف، نقل الكلمة،

كتابة الجملة السهلة، كتابة الجملة من النص

أو الحوار، إجابة الأسئلة، الإملاء، كتابة

v

$$
\text { الإنشاعُ المقيدة ثم الحرة. }
$$

ثانيا. كتابة الحروف: في مرحلة كتابة الحروف

يحسن المدرس مراعات ما يلى : يكر

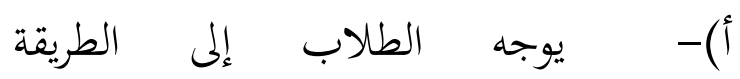

الصحيحة لمسك القلم، لأن غياب

هذا التوجيه يؤدي إلى عادات غير

مناسبة.

ب)- يوجه المدرس طلابه إلى الطريقة

الصحيحة للجلوس أثناء الكتابة

والظهر معتدل والدفتر أمام الطلاب

$$
\text { بزاوية ميل خفيفة. }
$$

${ }^{6}$ Radliyah Zaenuddin Dkk. Metodologi \& Strategi Alternatif Pembelajaran Bahasa Arab. (Yogyakarta. Pustaka Rihlah Group. 2005) ce. 1. Hal. 81.

${ }^{7} \mathrm{M}$ abdul hamid Dkk. Pembelajaran bahasa arab_pendekatan metode, strategi, materi dan media. (UIN malang press. 2008) cet. 1 hal. 49.

$$
\text { يتناسب منها مع الأفكار التى يريد الكاتب }
$$

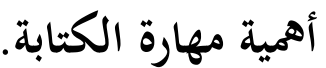

الكتابة وسيلة من وسائل الاتصال

التى بواسطتها يمكن للتلميذ أن يعبر عن أفكاره وأن يقف على أفكار غيره وأن يبرز

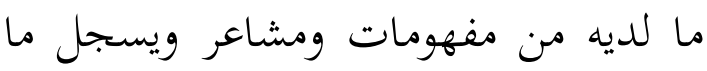
يود تسجيله من حوادث ووقائع · ويقرر أهمية الكتابة ابن خلدون في مقدمته فيرى أهما من جملة الصنائع المدنية المعاشية فهى ضرورية اجتماعية اصطنعها الإنسان لذلك تكون نابعة في نموها وتطورها لتقدم العمران وبها يتميز الإنسان عن الحيوان وتتأدى لئى

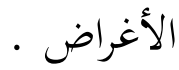

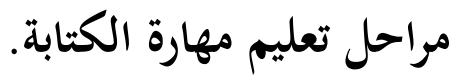
لتعليم مهارة الكتابة مراحل مختلفة

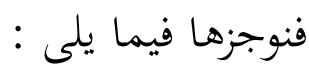

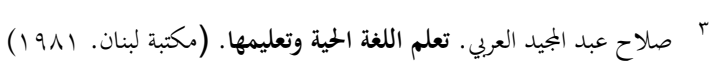
ص : : 11

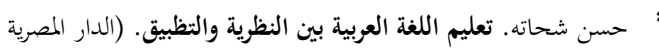

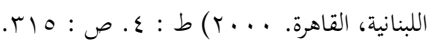

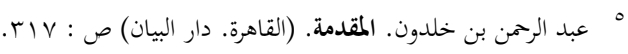


رابعا. الإملاء: بعد أن يتدرب الطلاب على

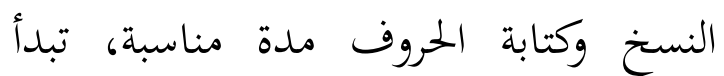
مرحلة الإملاء التى تكشف عن قدرة الطلاب

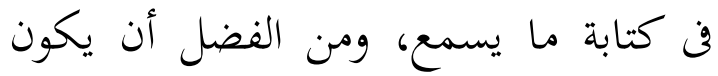
الإملاء بداية في مادة مألوفة قد قرأها الطلاب ونسخوها.

خامسا. الكتابة المقيدة: وهي ما يسمى

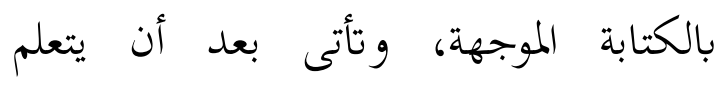
الطلاب كتابة الحروف والنسخ والإملاء. سادسا. الكتابة الحرة: هناك بعض الأمور التنظيمية التى يجب أن يرشد المدرس طلابه

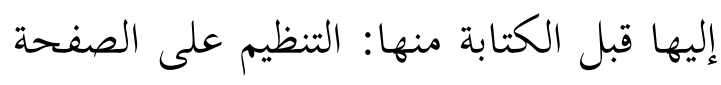
التى يكتب عليها من حيث المامش وكتابة التاريخ والموضوع والكتابة بأى نوع من أنواع الكاع وكنابة الأقلام وشكل الكتابة.

الإملاء. مفهوم الإملاء وأهميته.

قال حسن شحاته أن الإملاء هو نظام لغوى معين. موضوعه الكلمات التى

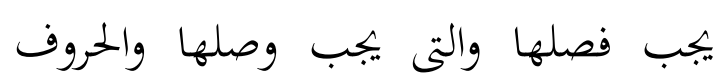

يوجه المدرس طلابه إلى التناسق فن الكتابة، ويككن تدريب الطلاب على لونى دفاتر خاصة مسطرة قبل الكتابة على كراسة الخط. ضرورة توحيد المسافات أقصر من كراس المطن المسافات بين كلمة الجملة الواحدة وتوحيد هذه المسافات. هـ)- يوجه المدرس طلابه إلى الكتابة بخطوط مستقيمة أفقية متوازية. و) - ميستحسن أن يكون الكتابة

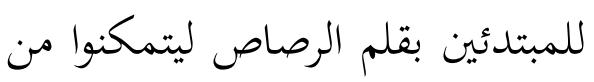
تعديل أخطائهم. من الفضل أن يكتب الطلاب فن الفماتم

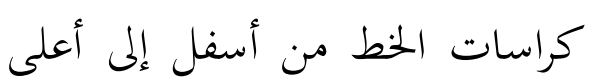

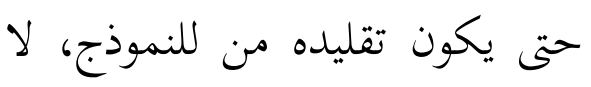
تقليده للسطر الذى يكتبه عندما يكتب من أعلى إلى أسفل. ثالثا. النسخ: بعد أن يتدرب الطلاب غلى إلى الثل كتابة الحروف منفصلة ومتصلة يكلفهم المدرس بنسخ فقرات معينة من كتاب القراءة، فقرات محددة، ليتمكن المدرس من تصويبها.

^ محمد بن إبراهيم الخطيب. طرائق تعليم اللغة العربية. (الرياض. مكتبة التوبة.

المملكة العربية السعودية. r. r. r) ص : 
عن الأخطاءٍ، فمما لاريب فيه أن الخظأ

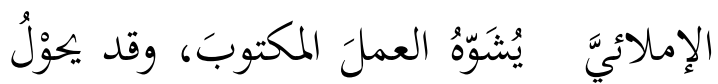

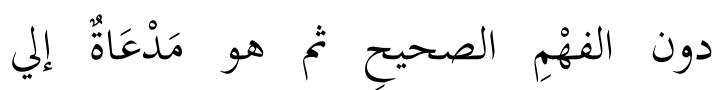

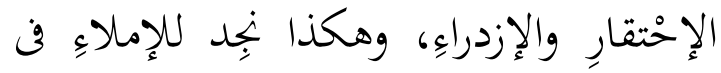
تَوَبِّيْهِ الرسمَ الصحيحَ للكلماتِ العربيةِ، هذه الأهيَّة التي هي فن غناءِ عن الإطنابِ

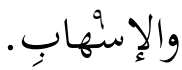

\section{أنواع الإملاء.}

ثمة تقسيمات متعددة للإملاء، فمنهم من يرى أن الإملاء نوعين أحدهما معروف أو 'معهود والآخر غير معروف أو غير معهود. وهناك من يرى أن للإملاء أربعة أنواع، هى:ا. الإملاء المنقول ب. الإملاء المنظور r. الإملاء الاستماعى ع. الإملاء

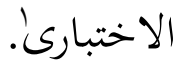

فالإملاء المنقول والمنظور من النوع المعهود، على حين أن الإملائين: الاستماعى والاختبارى من النوع غير المعروف. ويقصد من النوع المعهود أن الناشئة قد عرفوا النص النص من قبل ومرت بهم كلماته ورأوها بأم أعينهم.

r' عبد الجواد الطيب. دراسة في قواعد الإملاء. ( القاهرة . مكتبة الآدب.
الذى تزاد والحروف الذى تحذف والهمزة بأنواعها المختلفة سواء أكانت مفردة أو على تراد أحد حروف اللين الثلاثة والألف اللينة وهاء التأنيث وتاؤه وعلامات الترقيم والكلمات النوعية الواردة بالمواد الدراسية والتنوين بأنواعه والمد بأنواعه وقلب الحركات الثلاث وإبدال الحروف واللام الشمسية والقمرية. الإملاء مصدر من الفعل أمليت أو أمللت، ويعنى التلقين والنقل، تلقى على غيرك فينقل عنك. وهو الكتابة والبعد عن الخطأ في الرسم. وعند الوليد أحمد جابر أن الإملاء هو عملية التدريب على الكتابة الصحيحة لتصبح عادة يعتادها المتعلم ويتمك بواسطتها من نقل آرائه ومشاعره وحاجته وما يطلب إليه نقله إلى الآخرين بطريقة صحيحة. ولإملاعِ منزلةٌ كبيرةٌ بين الدراساتِ اللغويةِ،

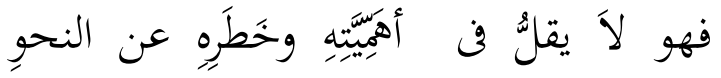
والصرْفِ وغيرهما، فلكلِّ غايتُه وهدفُه وأثرَه فن

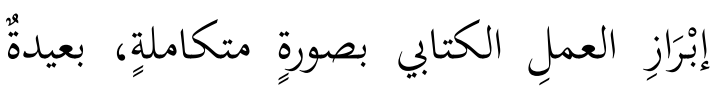

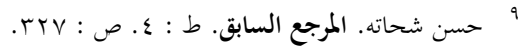

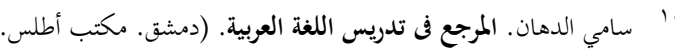

$$
\begin{aligned}
& \text { 19. : : 197r } \\
& \text { الوليد أحمد جابر. . تدريس اللغة العربية مفاهيم نظرية وتطبيقات عملية. }
\end{aligned}
$$

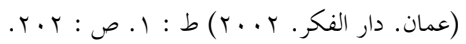


ثالثا. الاهتمام بالمعنى قبل الهجاء. يجب أن نربط الإملاء بالعمل التحريرى؛ فالهجاء دراسة لما هدف حيوى عندما يكون مرتبطا بالتعبير المكتوب، وعندما يكون أداة للكتابة وجزءا مكملا للعمل التحريرى لأن التناول العملى يعطى نتائج طيبة.

رابعا. الوسائل التى تساعد على اكتساب ملهارات الإملاء الصحيح تتمثل فن القراءة بإمعان، وتوضيح مخارج الحروف، والاهتمام بالإملاء في كل الواجبات المنزلية، واستخدام السبورة في كتابة الكلمات الجديدة، ومعرفة القواعد العملية المحددة مع التركيز على التطبيق.

نخلص مما سبق إلى أن الأسس التى تخدم الإملاء هى الإهتمام بالمعنى وإظهار مظاهر الحروف وربط الإملاء بالأعمال التحريرية والاهتمام بالهجاء فن القراءة والتعبير والواجبات المنزلية وحصر القواعد الشاذة والتطبيق عليها بطريقة منهجية وتدريب
أما غير المعهود فيقصد به النوع الذى لم يطلع عليه الناشئة، وإنما يستمعون إليه من غير أن

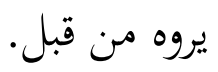
أسس تدريس الإملاء. هناك مجموعة من الأسس العامة التى يمكن أن تفيد لو سلف إليها المعلم خبرته بتلاميذه، وتمنه من مادته. وهذه الأسس :

أولا. تدريب الخطأ على الإصغاء إلى المعنى ومخارج الحروف. وتدريب اللسان على النطق الصحيح وتعود رسم الحروف والألفاظ والسيطرة على الصعوبة التى تخالف فيها الكتابةُ النطقَ ومعرفة قواعد الهجاء وكتابة موضوعات إنشائية قصيرة سبق معالجتها شفويا. ثانيا. الاهتمام بالتذكر والتدريب المستمر عن طريق مطالبة التلاميذ عن يذكروا عدة أسطر، تم نمليها عليهم في اليوم التالى، واضعين في

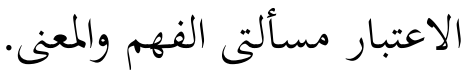


التذكر والتناول العملى للإملاء بما يحقق أولا. الطلاقة في الكلام والفصاحة في

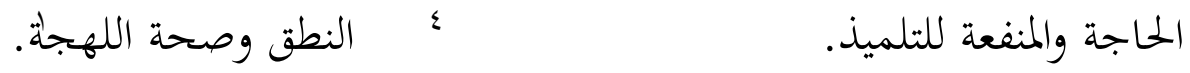
ثانيا. أن يكون له صوت متلئ رزين $\cdot \tau^{ض \lg }$ ثالثا. القدرة على اختيار الموضوع المناسب التربوي. رابعا. القدرة علي قطع جمل في نص إلي قطع مالائمة لا تخل بالفهم. خامسا. فهم المقالة فهما جيدا. سادسا. المهارة في توزيع الأوقات.

سابعا. قوة الملاحظة خصوصا في الإصلاح

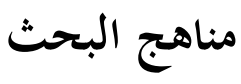
منهج البحث.

المنهج الذى استخدمه الباحث في طرق تصحيح الأخطاء الإملائية. يمكن للمدرس نفسه أن يتبع الطرائق متعددة في تصحيح الإملاء، نذكر منها : ا ـ أن يعمد المدرس نفسه إلى تصحيح الكراسة. r. أن يتبادل التلاميذ الكراسات. r. أن يصحح كل تلميذ أخطاءه. وللمدرس الحرية في اختيار الطريقة الملائمة والمناسبة. وعند محمود رشدى خاطر هى: ا. أن يصحح التلاميمذ أخطاءه بنفسه ولنفسه. r. أن يتبادل التلاميذ الكراسات. r. أن يصحح المعلم الدفاتر بنفسه، وهذا التصحيح إما أن يكون داخل الفصل وأمام كل تلميذ وحتى يتابع المخطئ تصحيح خطأه ويسأل عما لا يفهم. وهى تصلح للفصول القليلة هذا البحث هو المنهج التجريب الذي تنجز وعلى شرط شغل التلاميذ يعمل آخر فيها التجربة. ويعتبر المنهج التحريى" أقرب مناهج البحوث لحل المشاكل بالطريقة 10 كلية المعلمين الإسلامية بمعهد دار السلام كونتور للتربية الإسلامية الحديثة.

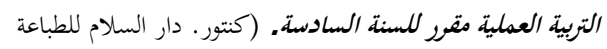

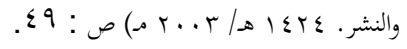

1 Sugiyono. Metode Penelítian Kuantitatif, Kualitatif dan R\&D. (Bandung. Alfabeta. 2010) Cet : 11. Hal : 107. كالقراءة الحرة. 1 الصفات اللازمة لمدرس الإملاء هي: 
للبنين فونوروكو. هـ الكتب والبحوث في مجال تعليم اللغة العربية للناطقين بغيرها.

\section{أسلوب تحليل البيانات}

لتحليل البيانات استخدم الباحث التحليل الإحصائي الوصفي ( Descriptive .(Statistic Analysis

كانت النتائج لهذا البحث كمايلي:

\section{نتائج البحث}

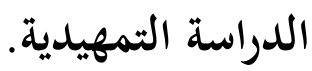

من ملاحظة الباحث المعلم ومن المقابلة مغ المعلم، وجد الباحث أن المعلم في من معهد الإيمان الإيمان الإسلامى يعلم الإملاء

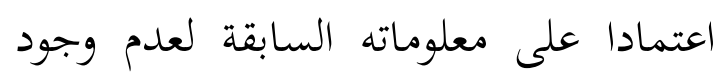
كتاب لمادة الإملاء يشكل دليلا له في تعليم الإملاء، والمنهج والمادة التعليمية أى الكتاب

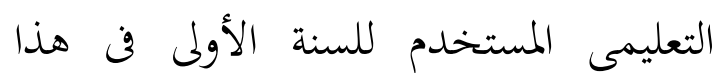
المعهدلم يكن موجودا فتحليله بإنتاج هذا لـاني الكتاب المصمم. ومن ملاحظة الطلاب، رأى الباحث أن بعض الطلاب لهم رغبة كبيرة في تعلم مادة الإملاء، فاستمعوا إلى ما لمان

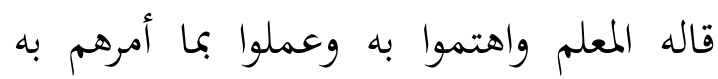

العملية. والتجريب سواء تم في المعمل أوفى قاعة الدراسة أوفن أى بجال آخر. ويكون تعريف البحث التجريبى بأسلوب بسيط أنه بحث يستخدم التجربة في إثبات الافتراض أوبحث يثبت الافتراض على طريق التجربة.

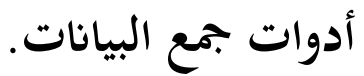
كانت أدوات جمع البيانات في هذا البحث هي: الـ الملاحظة. ب. الاستبانة.

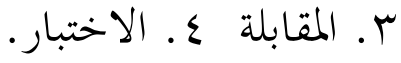
مصادر البيانات المراد بمصادر البيانات هنا هو المدار البحثي الذي تصدر منه البيانات. وفي هذا البحث تتكون من: ا. ـ مدير كلية المعلمين الإسلامية بععهد الإيمان الإسلامى للبنين فونوروكو. r. معلم مادة الإملاء. ب. ب. الوثائق الموجودة مثل إعداد المدرس وكراسات الطلاب. ع. طلاب السنة الأولى كلية المعلمين الإسلامية بمعهد الإيمان الإسلامى

IV ذوقان عبيدات وآخرون. البحث العلمى مفهومه أدواته أساليبه.

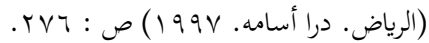

1 Suharismi Arikunto, Prosedur Penelitian Suatu Tindakan Praktik. (Jakarta:

Rineka Cipta, 2010) Cet : 14. Hal : 172. 


\section{تصميم مادة الإملاء.}

قام الباحث بتصميم مادة الإملاء، وصمم كتابا لمادة الإملاء لطلاب السنة الأولى بكلية المعلمين الإسلامية بعهدد الإيمان

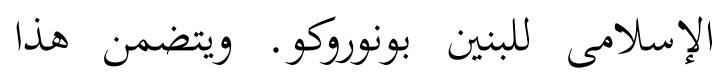
الكتاب على؛ المقدمة وكلمة عن تعليم الإملاء وأنواع الإملاء وطرائق تدريسه وطرق الفعاب تصحيح الإملاء والصفات اللازمة لمعلم الإملاء وملازمة المعلم البيان المعارف الآتية وبعض الملاحظات لقارئ الإملاء والمتويات والمادة الإملائية من الإملاء الأول إلى الإملاء الثلاخثن.

والتركيز فن بعض الأمالى المتقدمة في

هذا الكتاب على أحد عشر بابا، وهى: 1. الحروف ذات الأصوات المتقاربة فن الإملاء الأول. r. حروف المد في الإملاء الثانى. r.

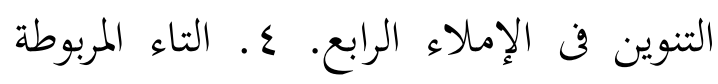

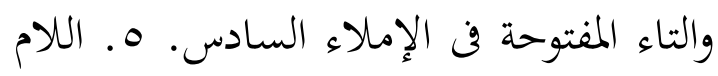
القمرية واللام الشمسية في الإملاء الثامن. T. بعض الحروف الجر والهمزة في الإملاء العاشر. V. الضمائر فن الإملاء الثان عشر. 1. النعت والمنعوت فن الإملاء الخامس. 9.
المعلم وأن بعضهم لم يهتموا كذلك، مثل التحدث مع زملائهم. من المقابلة مع المعلم، وجد الباحث أن المشكلات التى يواجهها المعلم عند التعليم

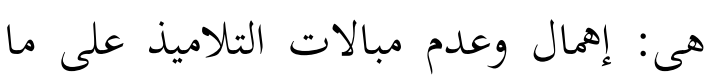
يملي عليه المعلم فتحليله بتوجيه وإرشاد التلاميذ لأن يهتم ويبالي على ما بملي عليه المعلم بطريقة وضع أقلامهم على المكتب.

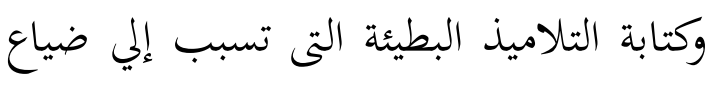
الوقت فتحليله بإكثار التدريبات في الإملاء

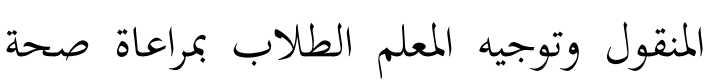
أيديهم. ضحالة ذكاء التلاميذ وشرود فكره عند الإملاء فتحليله بإكثار التدريبات في

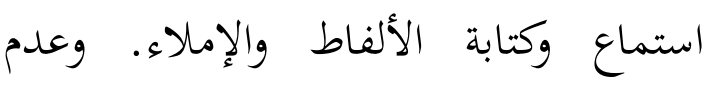
إطاعة أمر المعلم عند إلقاء قطع الإملاء فتحليله بالتوجيهات والارشادات والنصائح بأن الطاعة هى سر النجاح، وعدم إرهاف

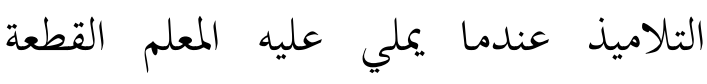
المختارة من المقالة فتحليله بتوجيه وإرشاد التلاميذ لأن يهتم جيدا على ما يملي عليه

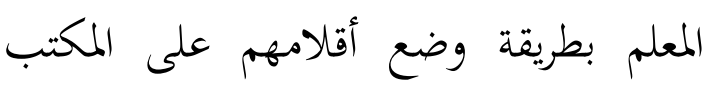
وبنظر فم الأستاذ. 


\begin{tabular}{|c|c|c|c|}
\hline $1 \ldots$ & $\Lambda$. & عمران غلام &.$r$ \\
\hline 70 & ro & فرادانا & $r$ \\
\hline 9 . & 70 & محمد عبد & . $\varepsilon$ \\
\hline $1 \ldots$ & $\Lambda$. & آصلح الرزق & .0 \\
\hline $1 \cdots$ & 10 & باغوس & .7 \\
\hline $2 \cdot$ & 10 & ونطو & . V \\
\hline 70 & 00 & عبد الملكك &.$\wedge$ \\
\hline 0 . & ro & صديق & .9 \\
\hline ₹० & $r$ & عارف & .1 . \\
\hline 0. & ro & حممد إفبال & .11 \\
\hline$\wedge$. & 00 & إروين فقه & $.1 \%$ \\
\hline 10 & 7. & محمد راغيل & .11 \\
\hline
\end{tabular}

الأماكن والأوصاف في الإملاء السابع عشر. • 1. الفرق بين رسم الحروف وصوته في الإملاء العشرون. الـ الإضافة في الإملاء الثانى والعشرون، والباقى تدريب الطلاب على بعض المهارات الإملائية التي سبقت دراستها. وكان الكتاب المصمم الذى صمم الباحث هو على ما حصل الباحث من الاستبيان والمقابلة والملاحظة والاختبار. بيانات الاختبار القبلي والبعدي. قبل إجراء عملية التعليم بالمادة المصصمة للإملاء قام الباحث بالاختبار القبلي والبعدي لمعرفة قدرة الطلبة في مهارة الكتابة. واسترك فيه أربعة عشر طالبا، وحصل على النتائج كما في الجداول التالي:

أ)- مقارنة نتائج الاختبار القبلي والبعدي.

\begin{tabular}{|c|c|c|c|}
\hline الاختيجة & الاختيجة & الإسم & الرقم \\
\hline$\wedge$. & 0. & زلني جعفر & .1 \\
\hline
\end{tabular}




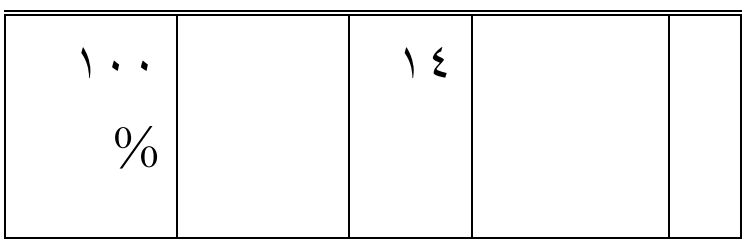

ومن هنا نعرف أن قدرة الطلاب في

الإملاء قبل تطبيق الكتاب المصمم هى:

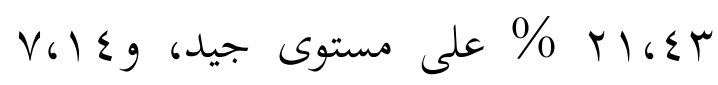

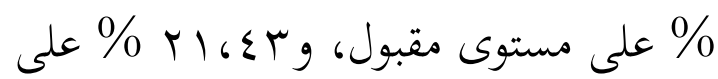

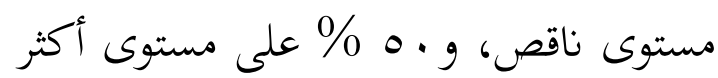
ناقصا. ولمعرفة النتيجة المعدلة استخدم

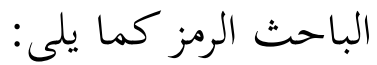

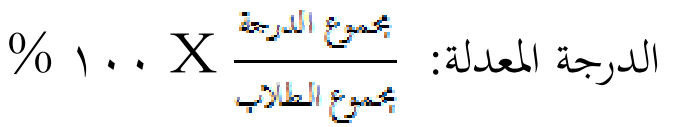
$.016 \varepsilon r=\% \quad 1 \ldots X \frac{720}{14}$

من نتيجة المعدلة السابقة، حسب المعيار المستخدم في هذا البحث، نعرف أن قدرة الطلاب في الإملاء قبل تطبيق الكتاب المصمم على مستوى " ناقص "، هذه كما دلت نتيجتهم المعدلة هى بـ؛ ج)- نسبة مائوية لنتيجة الطلاب في

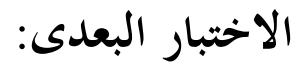

\begin{tabular}{|l|l|l|l|l|}
\hline رقم & (لدرجة & & \\
\hline
\end{tabular}

\begin{tabular}{|r|r|r|r|}
\hline 1. & $\varepsilon$. & . 1 عمد فكرى & \\
\hline \hline 1.1. & $V Y$. & الجمموع & \\
\hline
\end{tabular}

ب)- نسبة مائوية لنتيجة الطلاب فى الاختبار القبلى:

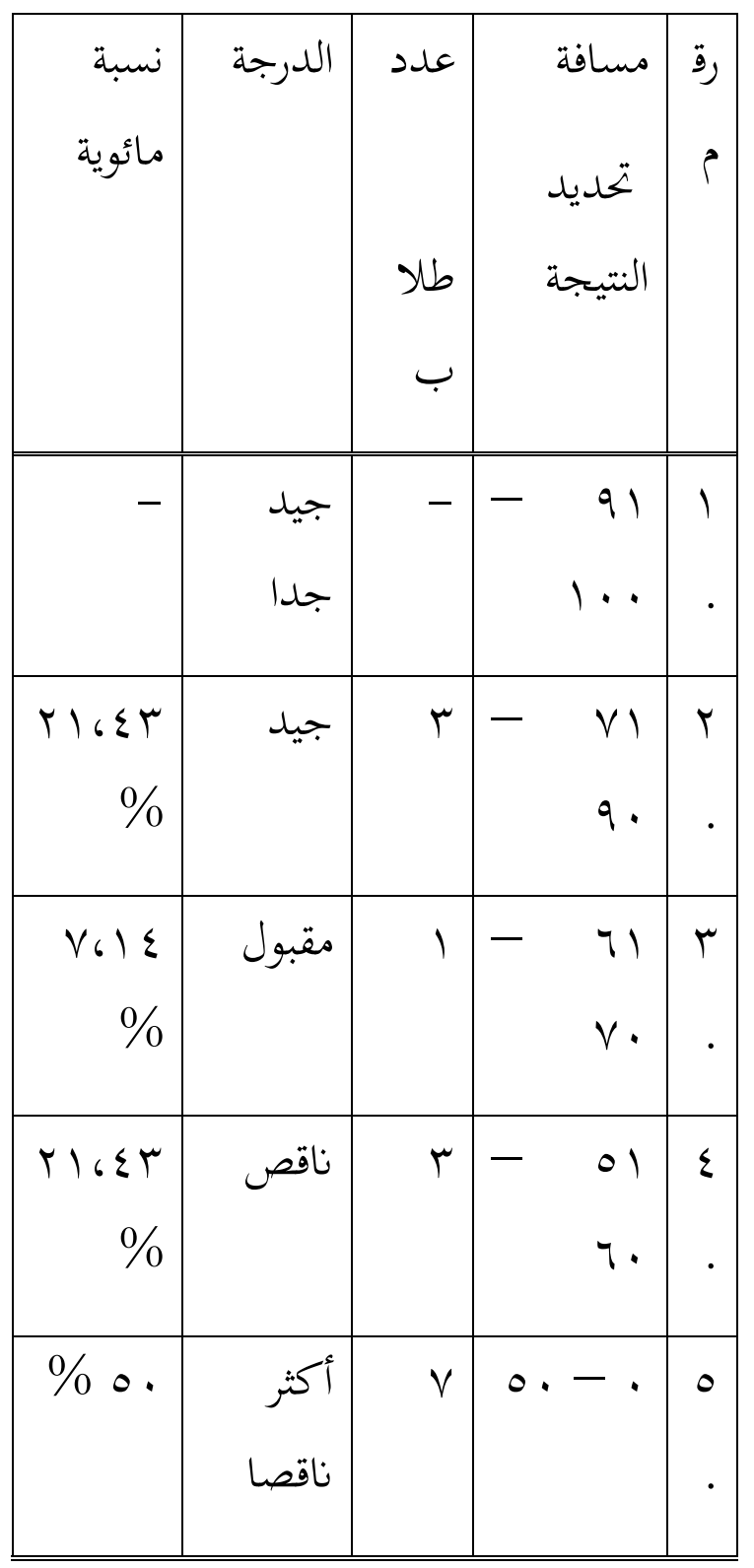


ناقصا. و ولمعرفة النتيجة المعدلة استخدم الباحث الرمز كما يلى: (n)

الدرجة المعدلة:

VYG $\leqslant=\% 1 \ldots X \frac{1010}{14}$

من نتيجة المعدلة السابقة، حسب

المعيار المستخدم في هذا البحث، نعرف أن قدرة الطلاب فن الإملاء بعد تطبيق الكتاب المصمم على مستوى " جيد "، هذه كما

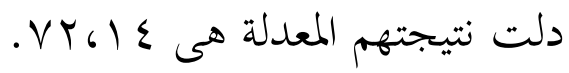

اعتمادا على حساب النتيجة الأخيرة عرف الباحث أن هناك فرقا واضحا بين نتيجة الاختبار القبلى والاختبار البعدي وهى

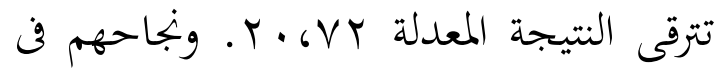

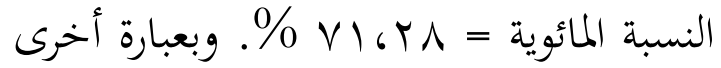
أن إنتاج واستخدام الكتاب المصمم لمادة الإملاء لطلاب السنة الأولى كلية المعلمين الإسلامية بمعهد الإيمان الإسالامى للبنين بونوروكو من طرائق فعالة لتحليل صعوبة الطلاب ويساعدهم في ترقية مهارة الكتابة.

\begin{tabular}{|c|c|c|c|c|}
\hline مائوية & & طلاب & تحديد & \\
\hline $\begin{array}{r}r \mid 6 \leqslant r \\
\%\end{array}$ & جيد & r & $\begin{array}{r}-91 \\
1 \ldots\end{array}$ & .1 \\
\hline $\begin{array}{r}\text { rA, } 0 V \\
\%\end{array}$ & جيد & $\varepsilon$ & $\begin{array}{r}-v 1 \\
q .\end{array}$ &.$T$ \\
\hline $\begin{array}{r}1 \leqslant 6 \times 9 \\
\%\end{array}$ & مقبول & $r$ & $\begin{array}{r}-71 \\
v .\end{array}$ & r. \\
\hline $\begin{array}{r}\left.V_{6}\right) \leq \\
\%\end{array}$ & ناقص & 1 & $\begin{array}{r}-01 \\
7 .\end{array}$ & . \{ \\
\hline $\begin{array}{r}r \Lambda_{6} \circ V \\
\%\end{array}$ & أكثر & $\varepsilon$ & $\begin{array}{rr}- & . \\
& 0 .\end{array}$ & .0 \\
\hline $\begin{array}{r}1 \ldots \\
\%\end{array}$ & & $1 \varepsilon$ & & \\
\hline
\end{tabular}

وون هنا نعرف أن قدرة الطلاب فن

الإملاء بعد تطبيق الكتاب المصمم هى:

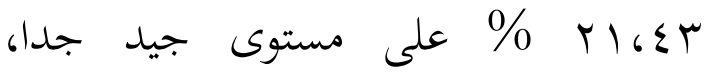

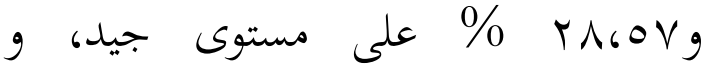

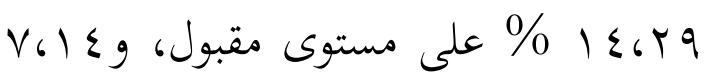

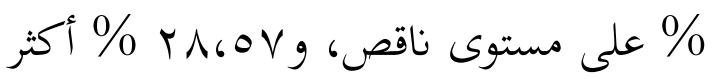


القاهرة. دار أسامة

للطبع.

حسن شحاته. ( ( . . ب). تعليم اللغة

العببية بين النظرية

والتظبيق. القاهرة. الدار

المصرية اللبنانية.

حمادة إبراهيم. (9AV) ( ) الاتجاهات

المعاصرة فى دووس اللغة

اللعربية واللغات الحية

الأخرى لغير الناطقين كجا.

القاهرة. دار الفكر.

ذوقان عبيدات وآخرون. ( 991 ( ).

البحث العلمى مغهومه

أدواته أساليبه. الرياض. درا

أسامه.

سامي الدهان. (س7 9 ( ). المرجع فى المه تلدريس اللغة العربية.

دمشق. مكتب أطلس.

صلاح عبد المجيد العربي. ( (9 ( ). تعلم

اللغة الحية وتعليمها . مكتبة

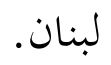

\section{خلاصة}

لتحسين تعليم مهارة الكتابة فن

الإملاء لطلاب السنة الأولى بكلية المعلمين الإسلامية بمعهد الإيمان الإسلامى للبنين بونوروكو خاصة، وبكلية المعلمين الإسلامية

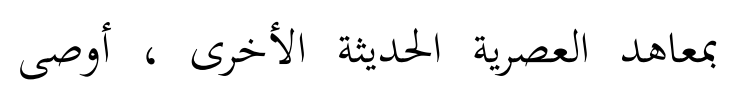
الباحث اعتمادا على ما توصل إليه بحثه بالأمور أن استخدام الكتاب المعين وتطبيقه فن التعليم لابد من أن يتناسب بمقدار

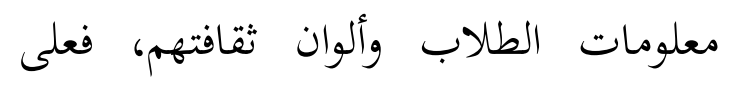
المعلم له الحرية فن تعيين هذا الكتاب المصمم في تعليم مادة الإملاء. وأن يتصف المعلم بالصفات اللازمة لمعلم الإملاء، كما هى

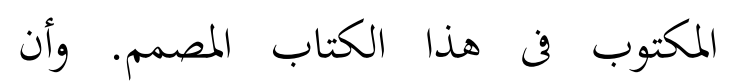
يتدرب معلم مادة الإملاء بأنواع الإملاء

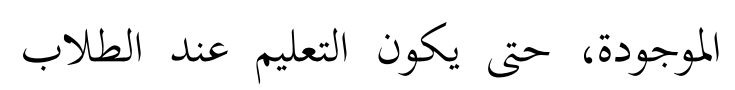
عملية مريحة مشوقة غير مملة. مراجع الكتابة حسن شحاته. (19AV) (1 ). تعليم اللغة العربية والتربية الدينية. 


$$
\begin{aligned}
& \text { القاهرة. دار الثقافة والنشر } \\
& \text { والتوزيع. } \\
& \text { حمود عطية الإبراشي. (س99 1) ). روح } \\
& \text { التربية والثعليم. القاهرة. دار }
\end{aligned}
$$

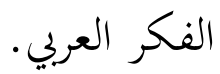

$$
\begin{aligned}
& \text { الوليد أحمد جابر. ( ( + • ( ) . تلدريس } \\
& \text { اللغة العببية مغاهيم نظرية } \\
& \text { وتطبيقات عملية. عمان. }
\end{aligned}
$$

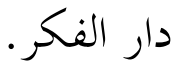

M Abdul Hamid Dkk. (2008). Pembelajaran

bahasa

arab_pendekatan

metode, strategi, materi

dan media. UIN malang

press. Cet. 1.

Radliyah Zaenuddin Dkk. (2005).

Metodologi \& Strategi

Alternatif Pembelajaran

Bahasa Arab.

Yogyakarta. Pustaka

Rihlah Group. Cet. 1.

Sugiyono. (2010). Metode Penelitian

Kuantitatif, Kualitatif

dan R\&D. Bandung.

Alfabeta. Cet : 11.

Suharismi Arikunto. (2010). Prosedur Penelitian Suatu Tindakan Praktik. Jakarta: Rineka Cipta. Cet : 14

$$
\begin{aligned}
& \text { عبد الجواد الطيب. (0 • • ( ). دراسة في } \\
& \text { قواعل الإماءء. القاهرة . } \\
& \text { مكتبة الآدب. ه ه . . . . } \\
& \text { عبد الرحمن بن خلدون. المقدمة. القاهرة. }
\end{aligned}
$$

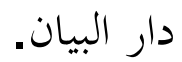

$$
\begin{aligned}
& \text { كلية المعلمين الإسلامية بمعهد دار السلام } \\
& \text { كونتور للتربية الإسالامية } \\
& \text { الحميثة. التربية العملية } \\
& \text { مقرر للسنة السادسة. }
\end{aligned}
$$

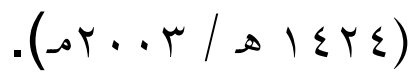

$$
\begin{aligned}
& \text { فونوروغو - كنتور • دار } \\
& \text { السالام للطباعة والنشر . } \\
& \text { حمد بن إبراهيم الخطيب. ( ( + . (Y). } \\
& \text { طرائق تعليم اللغة العوبية. } \\
& \text { الرياض. مكتبة التوبة. } \\
& \text { المملكة العربية السعودية. } \\
& \text { حمود رشدي خاطر ومصطفى رسالان. }
\end{aligned}
$$

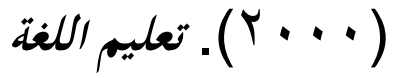

$$
\begin{aligned}
& \text { العربية والتربية الدينية. }
\end{aligned}
$$

